\title{
Article \\ Synergistic Regulation Mechanism of Inorganic Thermal Oxidation Coating and Poly (Vinylphosphonic Acid) (PVPA) Coating for High Load Bearing Superlubricity
}

\author{
Mengmeng Liu ${ }^{1}$, Zhifeng Liu ${ }^{1,2}$, Junmin Chen ${ }^{2}$, Liang Jiang ${ }^{3}$, Caixia Zhang ${ }^{1,2, *}$ and Xianyong Li ${ }^{1}$ \\ 1 Institute of Advanced Manufacturing and Intelligent Technology, Beijing University of Technology, \\ Beijing 100124, China; Liumengmeng@emails.bjut.edu.cn (M.L.); lzf@bjut.edu.cn (Z.L.); \\ lixianyong@emails.bjut.edu.cn (X.L.) \\ 2 Beijing Key Laboratory of Advanced Manufacturing Technology, Beijing University of Technology, \\ Beijing 100124, China; chenjunmin@emails.bjut.edu \\ 3 School of Mechanical Engineering, Southwest Jiaotong University, Chengdu 610031, China; \\ jiangliang@swjtu.edu.cn \\ * Correspondence: zhang-cx15@bjut.edu.cn; Tel.: +86-10-62391811
}

check for updates

Citation: Liu, M.; Liu, Z.; Chen, J.; Jiang, L.; Zhang, C.; Li, X. Synergistic Regulation Mechanism of Inorganic Thermal Oxidation Coating and Poly (Vinylphosphonic Acid) (PVPA) Coating for High Load Bearing Superlubricity. Appl. Sci. 2021, 11, 416 https://doi.org/10.3390/app11010416

Academic Editor: Marwan Al-Haik Received: 5 November 2020 Accepted: 31 December 2020 Published: 4 January 2021

Publisher's Note: MDPI stays neutral with regard to jurisdictional clai$\mathrm{ms}$ in published maps and institutional affiliations.

Copyright: (C) 2021 by the authors. Licensee MDPI, Basel, Switzerland. This article is an open access article distributed under the terms and conditions of the Creative Commons Attribution (CC BY) license (https:// creativecommons.org/licenses/by/ $4.0 /)$.

\begin{abstract}
A low friction coefficient and high bearing capacity can improve the service life of implants in the human body. In this study, we firstly investigate the mechanical properties of inorganic thermal oxide coatings on titanium alloy (Ti6Al4V). Tribological experiments were performed for different tribo-pairs under uniform conditions. The inorganic thermal oxide coating on Ti6Al4V formed at $300^{\circ} \mathrm{C}$ was found to have excellent tribological properties and can effectively improve the bearing capacity of Ti6Al4V. The organic poly (vinylphosphonic acid) (PVPA) on Ti6Al4V has excellent anti-friction properties, which can help achieve superlubricity. An inorganic thermal oxide/organic PVPA composite coating was fabricated on Ti6Al4V to obtain a surface with low friction and high bearing capacity. It is found that the presence of the thermal oxide doubled the bearing capacity of the composite coating compared to that of the PVPA coating alone. This study can serve as a guide for the modification of artificial joints.
\end{abstract}

Keywords: inorganic thermal oxide coating; organic PVPA coating; composite coating; bearing capacity; superlubricity

\section{Introduction}

Titanium alloys are widely used in medical implants such as artificial implants, sensors, stents, etc. They offer outstanding biocompatibility which is a major factor in their successful usage [1]. However, owing to the complex environment in vivo, the surface properties of implants require further improvements. Surface modification can be used to polish the surface of the titanium alloy, without destroying its bulk characteristics [2-4].

Surface modification strategies vary based on the application, especially considering biofouling and tribology. Polymer-based modifications are usually performed on surfaces that are prone to biofouling [5]. The hydrophilic property of modified coatings is the main reason for the adsorption resistance of biomolecules [6], such as poly(ethylene glycol) [7-9], and poly(sodium styrene sulfonate) [10]. Operational wear on artificial joints inside the human body can lead to implant failure. Consequently, techniques to improve the tribological properties of titanium alloys have received significant attention, and surface modifications using inorganic, organic polymer, and composite coatings have been proposed. Inorganic coatings can improve the wear resistance owing to the increased hardness with the coatings. Surface modification techniques such as oxidation treatment [11-15] and spraying $[16,17]$ can provide hard inorganic coatings. Diamond-like carbon (DLC), TiN, oxide ceramic coatings, etc., have also been studied. A complex of two-dimensional carbon materials with hard ceramic coatings is the most conventionally used method to reduce friction [18]. 
However, the main disadvantage of this method is that the coating is eventually stripped away due to the stress difference between two materials. Consequently, oxide coatings have become increasingly attractive, as the formation process of oxide coatings increases the adhesion between the coating and the substrate [19].

To solve the coating stripping problem, several researchers have recommended organic polymer coatings as they are linked to the metal surface by covalent bonds and have excellent behavioral properties. Furthermore, polymer coatings offer better biocompatibility compared to inorganic coatings. Hydrophilic polymer poly (2-methacryloyloxyethyl phosphorylcholine) (PMPC) brushes were grafted on to a porous metal surface and were found to significantly reduce the friction coefficient $[20,21]$. Ghosha used ultraviolet irradiation to graft PMPC on to the surface of a selective laser-melted titanium alloy. The modified alloy protected the implant from scratches at high loads [22]. In addition to its hydrophilic properties that prevent biofouling, poly(ethylene glycol) (PEG) has excellent tribological properties, and can be applied in water-based lubricants in the human body [23]. Poly(vinylphosphonic acid) (PVPA) coatings offer excellent friction reduction. The friction coefficient of PVPA coatings is less than 0.01, which indicates the superlubricity state [23,24]. PVPA-modified titanium is velocity independent and can be used in different implants [25]. The layer-by-layer (LbL) assembly technique can be used to construct multilayer polymer films on titanium. Modified titanium with thicker polyelectrolyte multilayers has superior tribological properties [26]. Despite good anti-frictional properties, a critical disadvantage of soft polymer organic coatings is their poor bearing capacity.

The synergy of inorganic and organic materials can help reduce their individual deficiencies. Biphasic structures consisting of both soft and hard substances can provide high load bearing capacity and low friction. However, for in vivo applications, several important factors must be investigated such as the influence of the inorganic coating morphology on polymer linkage, feature matching of the various materials, cooperation mechanism between materials, etc. In this study, thermal oxide modification of a titanium alloy surface is performed at various temperatures to investigate the influence of temperature on the properties of the thermal oxide coating. Subsequently, PVPA coatings are grafted on to the thermal oxide coating. Tribological experiments are performed under uniform conditions to compare the performance of different tribo-pairs. Finally, the collaborative anti-friction mechanism of thermal oxide coating and PVPA is explored. The proposed composite coating offers high bearing capacity and low-friction at high stress, and can serve as a guide for reducing the wear of implants.

\section{Materials and Methods}

\subsection{Materials}

PVPA powder (97\%) was purchased from Sigma-Aldrich (St. Louis, MO, USA). Phosphate-buffered saline (PBS) was provided by J\&K Chemicals. Ti6Al4V foils $(100 \mathrm{~mm} \times 100 \mathrm{~mm} \times 1 \mathrm{~mm})$ were supplied by Goodfellow Cambridge Ltd. (Cambridge, UK). These foils were then polished using polishing slurry (Research Institute of Tsinghua University, Shenzhen) to achieve flat and smooth surfaces ( $\operatorname{Ra} \approx 2 \mathrm{~nm})[25,27]$. Polytetrafluoroethylene (PTFE) balls $(\mathrm{D} \approx 6 \mathrm{~mm})$ were purchased from Taobao, Inc. The corresponding elastic modulus was $500 \mathrm{MPa}$. The average roughness of the balls was about $280 \mathrm{~nm}$. All reagents were used in their as-received state, without purification.

\subsection{Preparation and Characterization of Inorganic Thermal Oxide Coatings}

A pit furnace (RJJ150X200) was used to heat the bare Ti6Al4V sample for $5 \mathrm{~h}$. The heating temperatures were $100{ }^{\circ} \mathrm{C}, 300{ }^{\circ} \mathrm{C}, 500{ }^{\circ} \mathrm{C}, 700{ }^{\circ} \mathrm{C}$, and $900{ }^{\circ} \mathrm{C}$, respectively. Consequently, different thermal oxide coatings were formed on the surface. The composition and conformation of the thermal oxide coatings were characterized by X-ray photoelectron (XPS). All spectra were obtained at a $90^{\circ}$ photoelectron take-off angle from the surface. Three spots on two replicates were analyzed on each measured surface. The surface morphology of the thermal oxide coatings was observed using field-emission scanning electron 
microscopy (Gemini SEM 300). The thickness of different inorganic thermal oxide coatings was investigated with the help of 3D measuring laser microscope (OLS4000).

$X$-ray diffraction (XRD, Bruker D8 Advance) with $\mathrm{Cu} K \alpha$ radiation over the $2 \theta$ range of $15-60^{\circ}$ was used to determine the phase of the thermal oxide coatings.

\subsection{Formation of PVPA Coatings}

The PVPA coatings were prepared using the horizontal evaporating self-assembly method. The pretreated foils were placed horizontally into a PTFE mold with square grooves $(10.2 \mathrm{~mm} \times 10.2 \mathrm{~mm} \times 10 \mathrm{~mm})$ and the required amount of PVPA aqueous solution was injected into the mold. Pretreated Ti6Al4V substrates with physically adsorbed PVPA coatings were obtained after the solvent was evaporated at $50{ }^{\circ} \mathrm{C}$ for $30 \mathrm{~h}$ in air. Finally, the samples were heated at $240^{\circ} \mathrm{C}$ for $6 \mathrm{~h}$, after which, the PVPA coatings were robustly tethered onto the pretreated Ti6Al4V surfaces.

\subsection{Nano Indentation Experiment}

Nanoindentation experiments were carried out using a NanoIndenter (G200). The indentation tests were performed at an ambient temperature of $27.5^{\circ} \mathrm{C}$ and a relative humidity of $45 \% .10$ indentations were performed on each sample and the hardness and Young's modulus of each sample were determined.

\subsection{Evaluation of Tribological Properties}

A universal micro-tribometer (UMT-3, BRUKER) was used to determine the tribological behavior of uncoated (bare) Ti6Al4V substrate, thermal oxide coatings, and complex coatings using the PBS lubricant. A PTFE ball was used to rub against the Ti6Al4V and the reciprocating movement mode was chosen. The temperature was controlled at $37^{\circ} \mathrm{C}$ during the sliding experiment, considering the average human body temperature. The initial contact pressure was approximately $22 \mathrm{MPa}$ and the average sliding speed was $12 \mathrm{~mm} / \mathrm{s}$.

\subsection{Microscopic Observation of Surface Morphology after Sliding}

The surface morphologies of the wear scars and scratches after sliding were observed using a stereo light microscope (BX53M, OLYMPUS, Tokyo, Japan). Before each test, the tribo-pairs were washed using PBS. The magnification of sample surfaces was 100 times. The tests were repeated at least thrice for each group.

\section{Results and Discussion}

\subsection{Modification of Surface Bearing Capacity of Ti6Al4V Using Inorganic Thermal Oxide Coating}

Previous studies have shown that performing inorganic thermal oxidation on biomedical titanium alloys is beneficial to the preparation of composite coatings [27]. Wang et al. also indicated that inorganic thermal oxidation can effectively improve the surface properties of biomedical titanium alloys for application in artificial cervical discs [28]. The effect of the characteristics of inorganic thermal oxide coatings on the friction characteristics of the surface of Ti6Al4V were investigated herein. The Ti6Al4V substrates were heat treated for $5 \mathrm{~h}$ at temperatures of $100{ }^{\circ} \mathrm{C}, 300{ }^{\circ} \mathrm{C}, 500{ }^{\circ} \mathrm{C}, 700{ }^{\circ} \mathrm{C}$, and $900{ }^{\circ} \mathrm{C}$. The surface of the bare Ti6Al4V substrate and the inorganic thermal oxide coatings were verified using XPS. Figure 1 presents the typical XPS survey scans over a binding energy of 0-1200 eV. As shown, the ordinate values gradually shifted upwards from the second line by 80,000, indicating a stark contrast. Line I in Figure 1 represents the typical XPS survey of the bare Ti6Al4V substrate. Lines II, III, IV, V, and VI represent the typical XPS surveys of Ti6Al4V after heat treatment at temperatures of $100{ }^{\circ} \mathrm{C}, 300{ }^{\circ} \mathrm{C}, 500{ }^{\circ} \mathrm{C}, 700{ }^{\circ} \mathrm{C}$, and $900{ }^{\circ} \mathrm{C}$, respectively. Compared to line $\mathrm{I}$, the $\mathrm{O} 1$ peaks of lines II-VI were significantly higher, which indicates that inorganic thermal oxide coatings were formed on the surface. Table 1 shows the relative oxygen content on the surface of Ti6Al4V before and after heat treatment. The 
oxygen content on the Ti6Al4V surface was highest at $300{ }^{\circ} \mathrm{C}$, which can lead to changes in its surface mechanical properties.

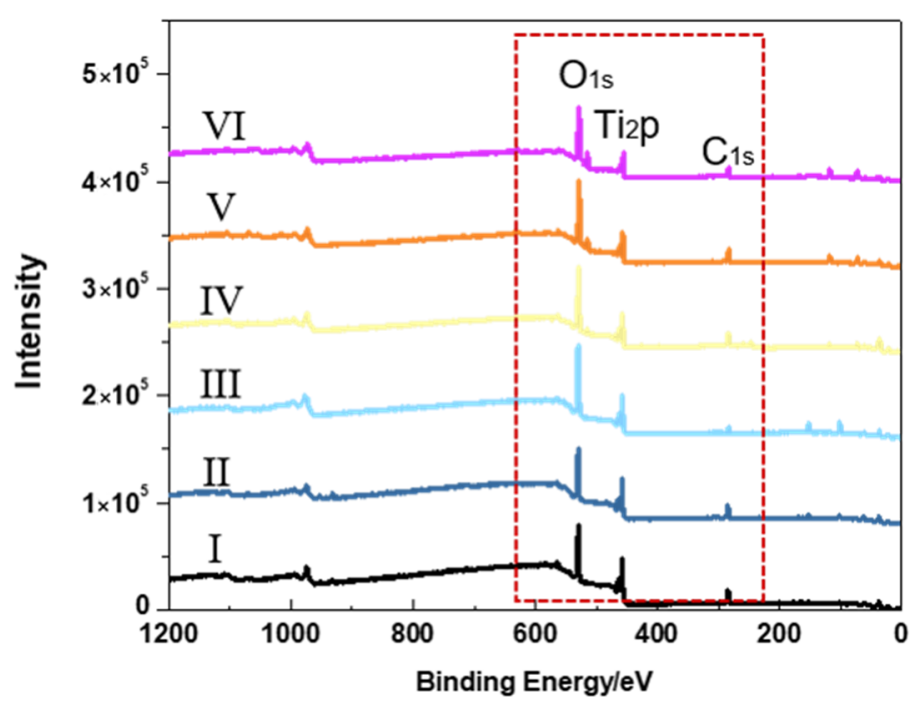

Figure 1. XPS scans of (I) bare Ti6Al4V, and (II-VI) heat-treated Ti6Al4V (II: $100{ }^{\circ} \mathrm{C}, \mathrm{III}: 300{ }^{\circ} \mathrm{C}$, IV: $500{ }^{\circ} \mathrm{C}, \mathrm{V}: 700^{\circ} \mathrm{C}$, and VI: $\left.900{ }^{\circ} \mathrm{C}\right)$.

Table 1. Relative content of O on Ti6Al4V surface at different temperatures.

\begin{tabular}{ccccccc}
\hline Temperature $\left({ }^{\circ} \mathrm{C}\right)$ & Bare & $\mathbf{1 0 0}{ }^{\circ} \mathbf{C}$ & $\mathbf{3 0 0}{ }^{\circ} \mathbf{C}$ & $500{ }^{\circ} \mathbf{C}$ & $\mathbf{7 0 0}^{\circ} \mathbf{C}$ & $\mathbf{9 0 0}{ }^{\circ} \mathbf{C}$ \\
\hline Oxygen content $(\%)$ & 50.45 & 56.46 & 78.25 & 55.95 & 60.09 & 65.14 \\
\hline
\end{tabular}

The surface morphologies of the Ti6Al4V substrates, before and after heat treatment at different temperatures, were examined using scanning electron microscopy (SEM) to explore the characteristics of the inorganic thermal oxide coatings. As shown in Figure $2\left(b_{1}-d_{1}\right)$, the surface morphologies of the inorganic thermal oxide coatings after heat treatment at $100{ }^{\circ} \mathrm{C}, 300^{\circ} \mathrm{C}$, and $500{ }^{\circ} \mathrm{C}$ are smooth, and are similar to the surface morphology of the bare Ti6Al4V substrate (Figure 2( $\left.\mathrm{a}_{1}\right)$ ). The thickness of different inorganic thermal oxide coatings was investigated with the help of stereo light microscope. Cross-sections of inorganic thermal oxide-coated Ti6Al4V were polished by sandpaper. Images that displays the cross section of the inorganic thermal oxide-coated Ti6Al4V were shown in Figure $2\left(\mathrm{a}_{2}-\mathrm{f}_{2}\right)$. The corresponding thickness of the inorganic thermal oxide coatings formed at $100{ }^{\circ} \mathrm{C}, 300{ }^{\circ} \mathrm{C}$, and $500{ }^{\circ} \mathrm{C}$ were $2 \mu \mathrm{m}, 3 \mu \mathrm{m}$, and $2 \mu \mathrm{m}$, respectively. This indicates that the inorganic thermal oxide coatings formed at $100{ }^{\circ} \mathrm{C}, 300{ }^{\circ} \mathrm{C}$, and $500{ }^{\circ} \mathrm{C}$ have a similar density and thickness. The structure of the inorganic thermal oxide coating that formed at $700{ }^{\circ} \mathrm{C}$ appeared uneven, as shown in Figure $2\left(\mathrm{e}_{1}\right)$. The corresponding thickness is $3 \mu \mathrm{m}$ (Figure 2( $\left.\mathrm{e}_{2}\right)$ ). The surface inhomogeneity became more obvious for the inorganic thermal oxide coating formed at $900{ }^{\circ} \mathrm{C}$ (Figure $2\left(f_{1}\right)$ ), while the thickness increased to $7.2 \mu \mathrm{m}$ (Figure 2(f $\left.\mathrm{f}_{2}\right)$ ). Therefore, above a certain temperature, the surface morphology and thickness of the inorganic thermal oxide coating changes significantly with the increase in temperature, which is possibly due to the change of phase of the inorganic thermal oxide coating. 

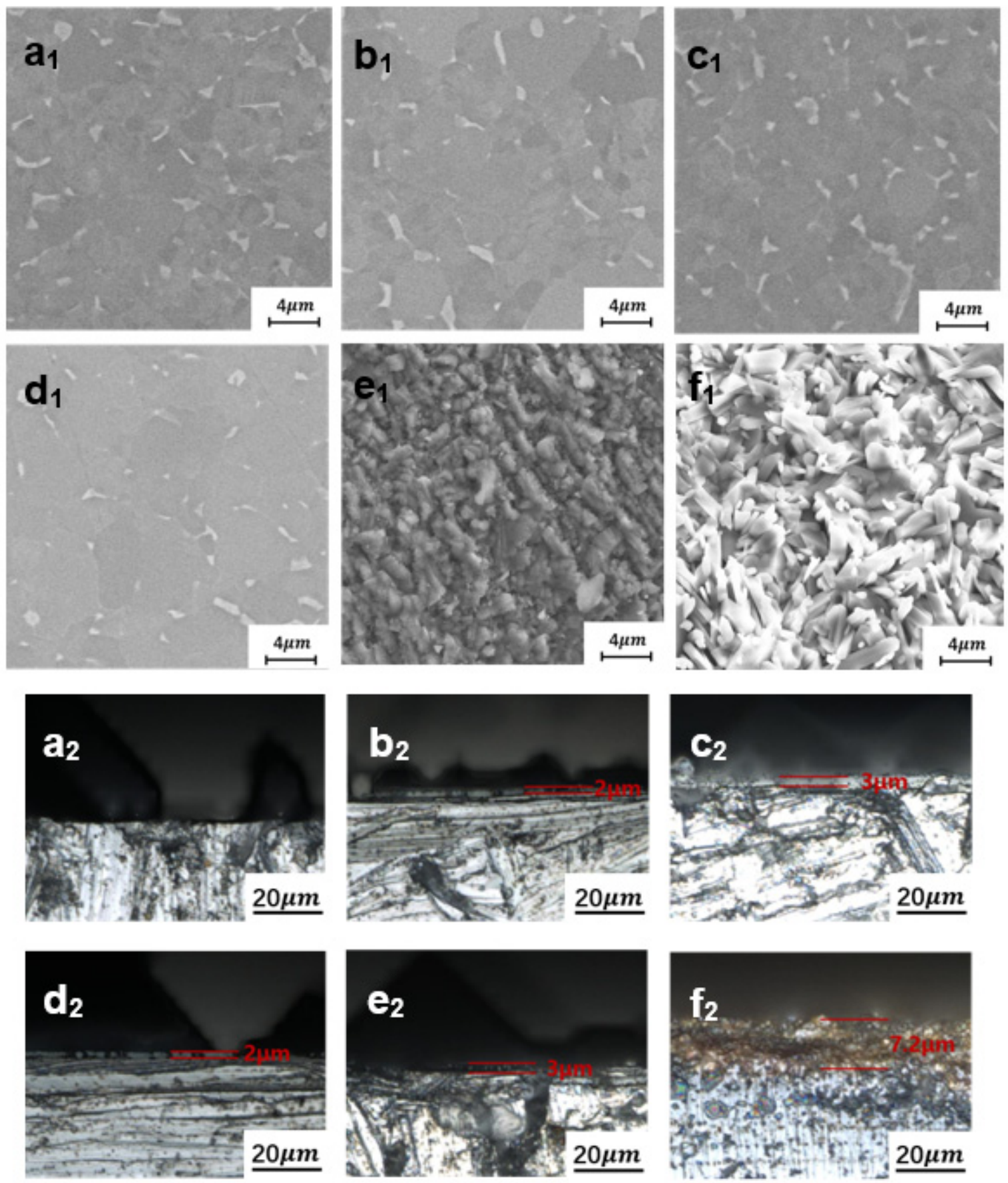

Figure 2. $\left(\mathbf{a}_{\mathbf{1}}-\mathbf{f}_{\mathbf{1}}\right)$ SEM micrographs of $\left(\mathbf{a}_{\mathbf{1}}\right)$ bare Ti6Al4V, and inorganic thermal oxide coatings formed at $\left(\mathbf{b}_{\mathbf{1}}\right) 100{ }^{\circ} \mathrm{C},\left(\mathbf{c}_{\mathbf{1}}\right)$ $300{ }^{\circ} \mathrm{C},\left(\mathbf{d}_{\mathbf{1}}\right) 500{ }^{\circ} \mathrm{C},\left(\mathbf{e}_{\mathbf{1}}\right) 700{ }^{\circ} \mathrm{C}$, and $\left(\mathbf{f}_{\mathbf{1}}\right) 900{ }^{\circ} \mathrm{C} ;\left(\mathbf{a}_{\mathbf{2}}-\mathbf{f}_{\mathbf{2}}\right)$ thickness of $\left(\mathbf{a}_{\mathbf{2}}\right)$ bare Ti6Al4V, and inorganic thermal oxide coatings formed at $\left(\mathbf{b}_{\mathbf{2}}\right) 100{ }^{\circ} \mathrm{C},\left(\mathbf{c}_{2}\right) 300{ }^{\circ} \mathrm{C},\left(\mathbf{d}_{\mathbf{2}}\right) 500{ }^{\circ} \mathrm{C},\left(\mathbf{e}_{2}\right) 700{ }^{\circ} \mathrm{C}$, and $\left(\mathbf{f}_{2}\right) 900{ }^{\circ} \mathrm{C}$ measured by stereo light microscope.

XRD analysis was carried out to further determine the state of the inorganic thermal oxide coatings on the surfaces of the titanium alloy. The representative XRD patterns of the thermal oxide coatings formed on the Ti6Al4V alloys at different temperatures are shown in Figure 3. At $100^{\circ} \mathrm{C}, 300{ }^{\circ} \mathrm{C}$, and $500{ }^{\circ} \mathrm{C}$, the $\alpha$ - $\mathrm{Ti}, \mathrm{Ti}(\mathrm{O})$, and $\mathrm{TiO}_{2}$ phases appeared [28,29], which are consistent with those that appeared on the bare Ti6Al4V. As the temperature increased, the phases of the inorganic thermal oxide coatings changed significantly. At $700{ }^{\circ} \mathrm{C}$ and $900{ }^{\circ} \mathrm{C}$, peaks at the diffraction angle $2 \theta=27.541,36.061,41.321$, and 54.281 appeared. These peaks can be indexed to the rutile structure of $\mathrm{TiO}_{2}[28,29]$. Relating 
phases of the thermal oxide coatings to corresponding surface morphologies (Figure 2), it can be inferred that $\mathrm{Ti}(\mathrm{O})$, and $\mathrm{TiO}_{2}$ phases will form a smoother surface, while the rutile structure of $\mathrm{TiO}_{2}$ will cause the surface to form irregular needle-like structure. The higher the temperature, the more pronounced this needle-like structure is.

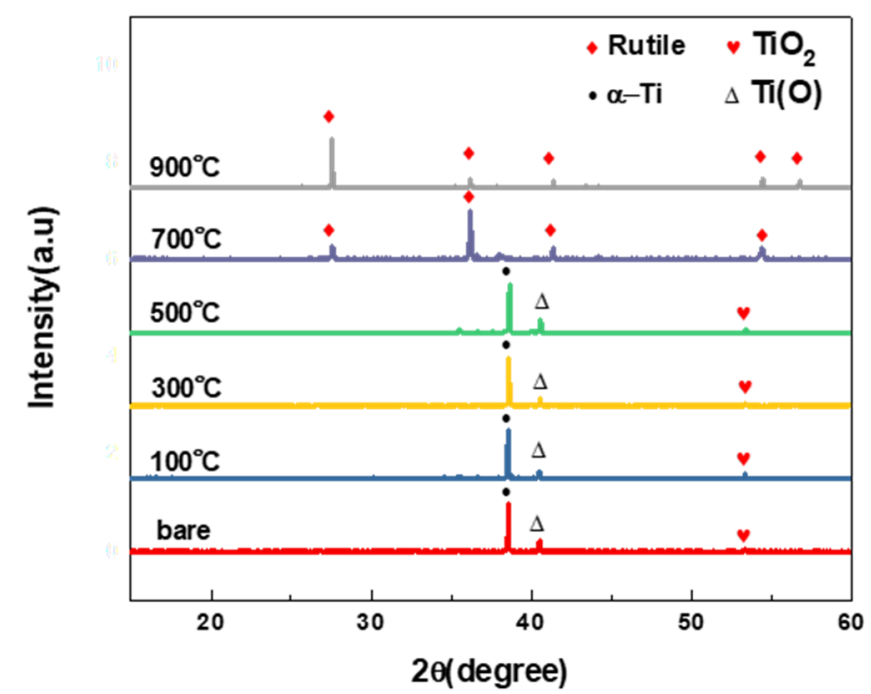

Figure 3. XRD patterns of bare Ti6Al4V and inorganic thermal oxide coatings formed at $100{ }^{\circ} \mathrm{C}$, $300{ }^{\circ} \mathrm{C}, 500{ }^{\circ} \mathrm{C}, 700{ }^{\circ} \mathrm{C}$, and $900{ }^{\circ} \mathrm{C}$.

Friction experiments were carried out using the UMT to study the tribological properties of the inorganic thermal oxide coatings. The friction experiments were performed in the reciprocating mode with an initial load of $2.5 \mathrm{~N}$ at $37^{\circ} \mathrm{C}$. Bare/thermal oxide coated Ti6Al4V and PTFE balls were sampled as tribo-pairs. A reciprocating frequency of $2 \mathrm{~Hz}$, corresponding to a sliding speed of $12 \mathrm{~mm} / \mathrm{s}$, was used in the experiment. PBS was used as the lubricant. The results of the bare and inorganic thermal oxide-coated surfaces are shown in Figure 4. The friction coefficients of the inorganic thermal oxide coatings formed at $700{ }^{\circ} \mathrm{C}$ and $900{ }^{\circ} \mathrm{C}$ are 0.288 and 0.240 , respectively, which are significantly higher than those formed at the lower temperatures. The friction coefficients of the inorganic thermal oxide coatings formed at $100{ }^{\circ} \mathrm{C}, 300^{\circ} \mathrm{C}$, and $500{ }^{\circ} \mathrm{C}$ were $0.025,0.027$, and 0.072 , respectively. Comparing the surface morphologies after sliding - as shown in Figure 4f,g-and combining the results of $\mathrm{XRD}$, the rutile phase of the inorganic thermal oxide coatings would significantly increase the friction coefficient. The surface wear of the inorganic thermal oxide coating formed at $300^{\circ} \mathrm{C}$ after the sliding test was minimal. Therefore, the inorganic thermal oxide coating formed at $300{ }^{\circ} \mathrm{C}$ has good friction and wear properties.

The inorganic thermal oxide coatings formed at $100^{\circ} \mathrm{C}, 300^{\circ} \mathrm{C}$, and $500^{\circ} \mathrm{C}$ had the same phase and micro-morphology, but different tribological properties, primarily due to the differences in the mechanical properties of the inorganic thermal oxide coatings formed at different temperatures. Nanoindentation experiments were performed to determine the hardness and elastic modulus of the bare Ti6Al4V and the thermal oxide-coated surfaces formed at three different temperatures, as shown in Figure 5a,b. The hardness of the bare Ti6Al4V and the inorganic thermal oxide-coated surfaces formed at $100^{\circ} \mathrm{C}, 300^{\circ} \mathrm{C}$, and $500{ }^{\circ} \mathrm{C}$ was $4.34 \pm 0.27 \mathrm{GPa}, 5 \pm 0.29 \mathrm{GPa}, 4.86 \pm 0.44 \mathrm{GPa}$, and $7.84 \pm 0.61 \mathrm{GPa}$, respectively. The corresponding elastic modulus were $134.2 \pm 4.9 \mathrm{GPa}, 124.6 \pm 4.4 \mathrm{GPa}$, $116.5 \pm 4.8 \mathrm{GPa}$, and $130 \pm 7 \mathrm{GPa}$, respectively. Therefore, heat treatment increases the surface hardness and decreases the elastic modulus. Considering the inorganic thermal oxide coating, the lower the hardness and the elastic modulus, the lesser the corresponding friction and wear. Therefore, compared to heat treatment temperatures of $100{ }^{\circ} \mathrm{C}$ and $500{ }^{\circ} \mathrm{C}$, a heat treatment temperature of $300^{\circ} \mathrm{C}$ offers better tribological properties. 

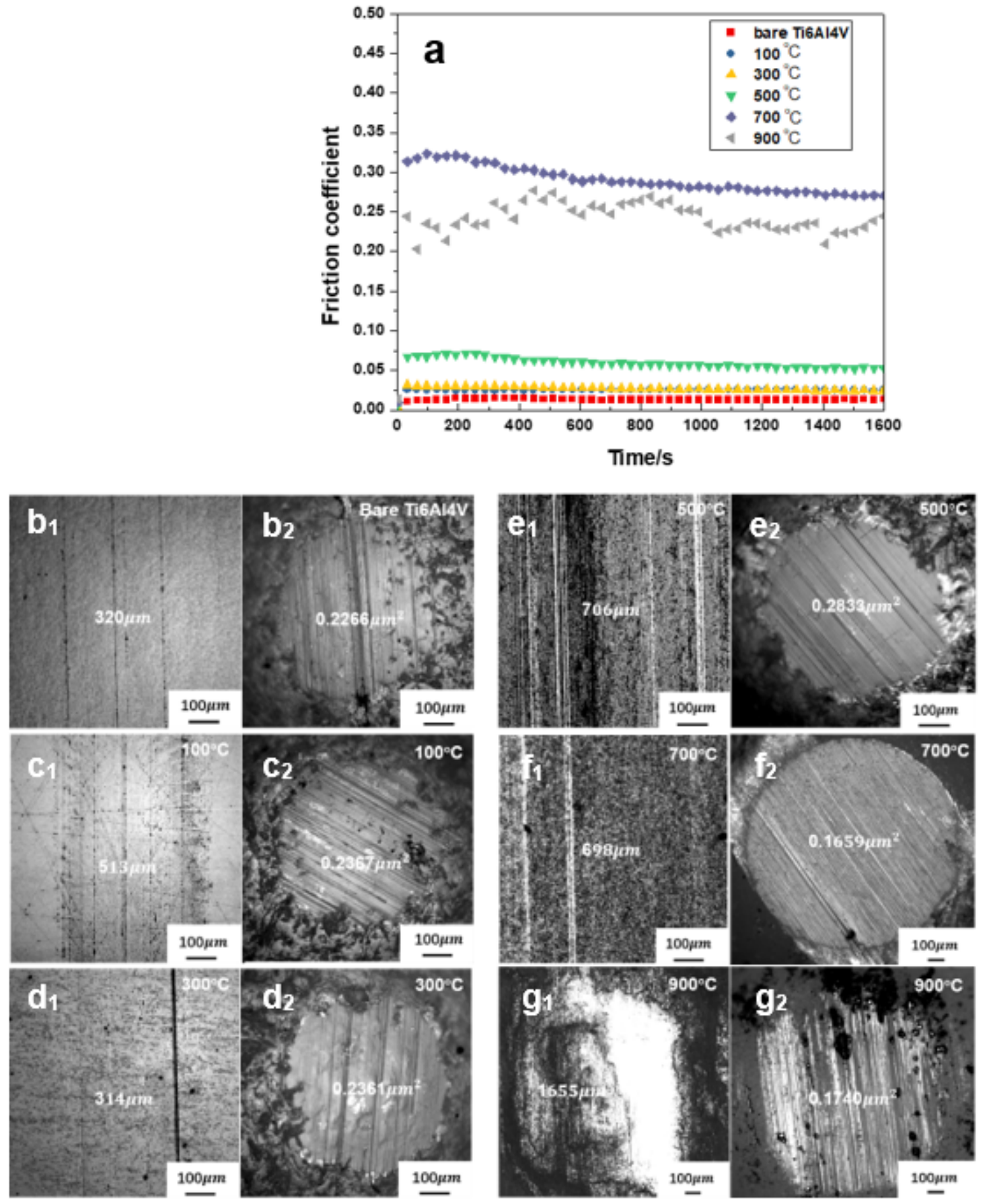

Figure 4. Tribological properties of bare Ti6Al4V and inorganic thermal oxide coatings formed at $100{ }^{\circ} \mathrm{C}, 300{ }^{\circ} \mathrm{C}, 500{ }^{\circ} \mathrm{C}$, $700{ }^{\circ} \mathrm{C}$, and $900{ }^{\circ} \mathrm{C}$ : (a) friction coefficient versus time, $\left(\mathbf{b}_{\mathbf{1}}-\mathbf{g}_{\mathbf{1}}\right)$ wear morphologies of $\left(\mathbf{b}_{\mathbf{1}}\right)$ bare Ti6Al4V, $\left(\mathbf{c}_{\mathbf{1}}-\mathbf{g}_{\mathbf{1}}\right)$ inorganic thermal oxide coatings formed at $\left(\mathbf{c}_{\mathbf{1}}\right) 100{ }^{\circ} \mathrm{C},\left(\mathbf{d}_{\mathbf{1}}\right) 300{ }^{\circ} \mathrm{C},\left(\mathbf{e}_{\mathbf{1}}\right) 500{ }^{\circ} \mathrm{C},\left(\mathbf{f}_{\mathbf{1}}\right) 700{ }^{\circ} \mathrm{C}$, and $\left(\mathbf{g}_{\mathbf{1}}\right) 900{ }^{\circ} \mathrm{C}_{,}\left(\mathbf{b}_{\mathbf{2}}-\mathbf{g}_{\mathbf{2}}\right)$ wear morphologies of PTFE balls $\left(\left(\mathbf{b}_{2}\right)\right.$ tribo-pair of the bare Ti6Al4V, $\left(\mathbf{c}_{2}-\mathbf{g}_{2}\right)$ tribo pairs of inorganic thermal oxide coatings formed at $\left(\mathbf{c}_{2}\right)$ $100{ }^{\circ} \mathrm{C},\left(\mathbf{d}_{\mathbf{2}}\right) 300{ }^{\circ} \mathrm{C},\left(\mathbf{e}_{2}\right) 500{ }^{\circ} \mathrm{C},\left(\mathbf{f}_{2}\right) 700{ }^{\circ} \mathrm{C}$, and $\left.\left(\mathbf{g}_{2}\right) 900{ }^{\circ} \mathrm{C}\right)$. 

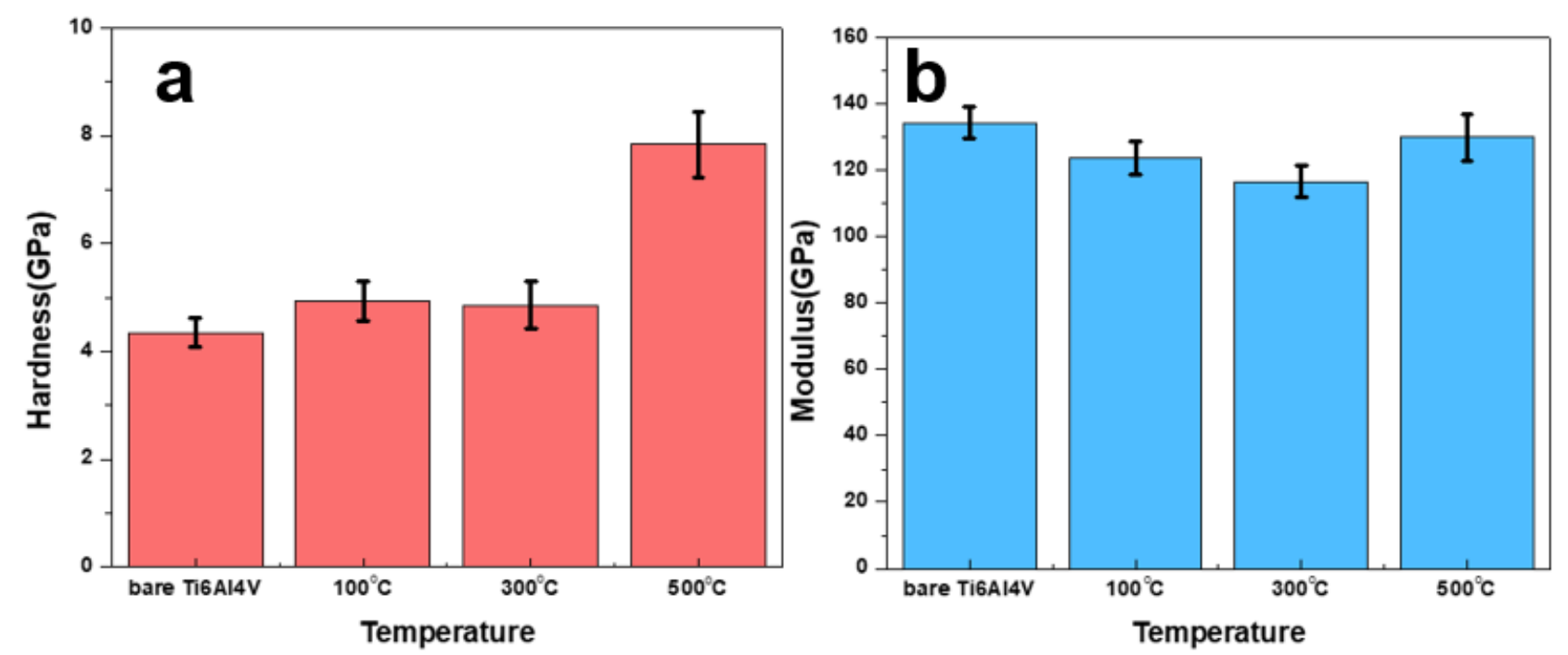

Figure 5. (a) Hardness and (b) elastic modulus of bare Ti6Al4V and inorganic thermal oxide coatings formed at $100{ }^{\circ} \mathrm{C}$, $300{ }^{\circ} \mathrm{C}$, and $500{ }^{\circ} \mathrm{C}$.

An interesting phenomenon was that the friction coefficient and wear of the bare Ti6Al4V were minimal with an initial load of $2.5 \mathrm{~N}$, as shown in Figure 4a. The friction coefficient of the bare Ti6Al4V increased with the increase in stress, as shown in Figure 6a. However, the friction coefficient of the inorganic thermal oxide coating formed at $300{ }^{\circ} \mathrm{C}$ did not change significantly with the increase in stress, as shown in Figure $6 \mathrm{~b}$. Above $2.5 \mathrm{~N}$, which corresponds to a stress of $22 \mathrm{MPa}$, the wear of the inorganic thermal oxide coating was always lower than that of the bare Ti6Al4V at the same load, as shown in Figure $6 \mathrm{c}-\mathrm{j}$, and the inorganic thermal oxide coating increased the bearing capacity of Ti6Al4V from 22 to $352 \mathrm{MPa}$. The increase in bearing capacity is primarily due to the increased surface hardness of the inorganic thermal oxide coating, as shown in Figure 5a. Therefore, the higher the hardness of the surface, the higher the bearing capacity.

The friction characteristics are closely related to the composition of the inorganic thermal oxide coating. For example, the inorganic thermal oxide coating mainly composed of rutile phase shows a higher friction coefficient. For the same inorganic thermal oxide coating composition, the friction properties are closely related to the elastic modulus of the surface. An ideal temperature value exists at which the inorganic thermal oxide coating has excellent tribological properties. In this study, a temperature of $300^{\circ} \mathrm{C}$ was selected for thermal oxidation treatment. Through friction experiments at different loads, the inorganic thermal oxide coating was found to increase the bearing capacity by a factor of 16. Essentially, inorganic thermal oxide coatings enhance the surface hardness, thereby increasing the bearing capacity of the surface. In addition, inorganic thermal oxide coatings can act as an intermediate boundary layer in composite coatings, improving the adhesion between the organic layer and the substrate. This has been demonstrated in previous studies as well [27]. 

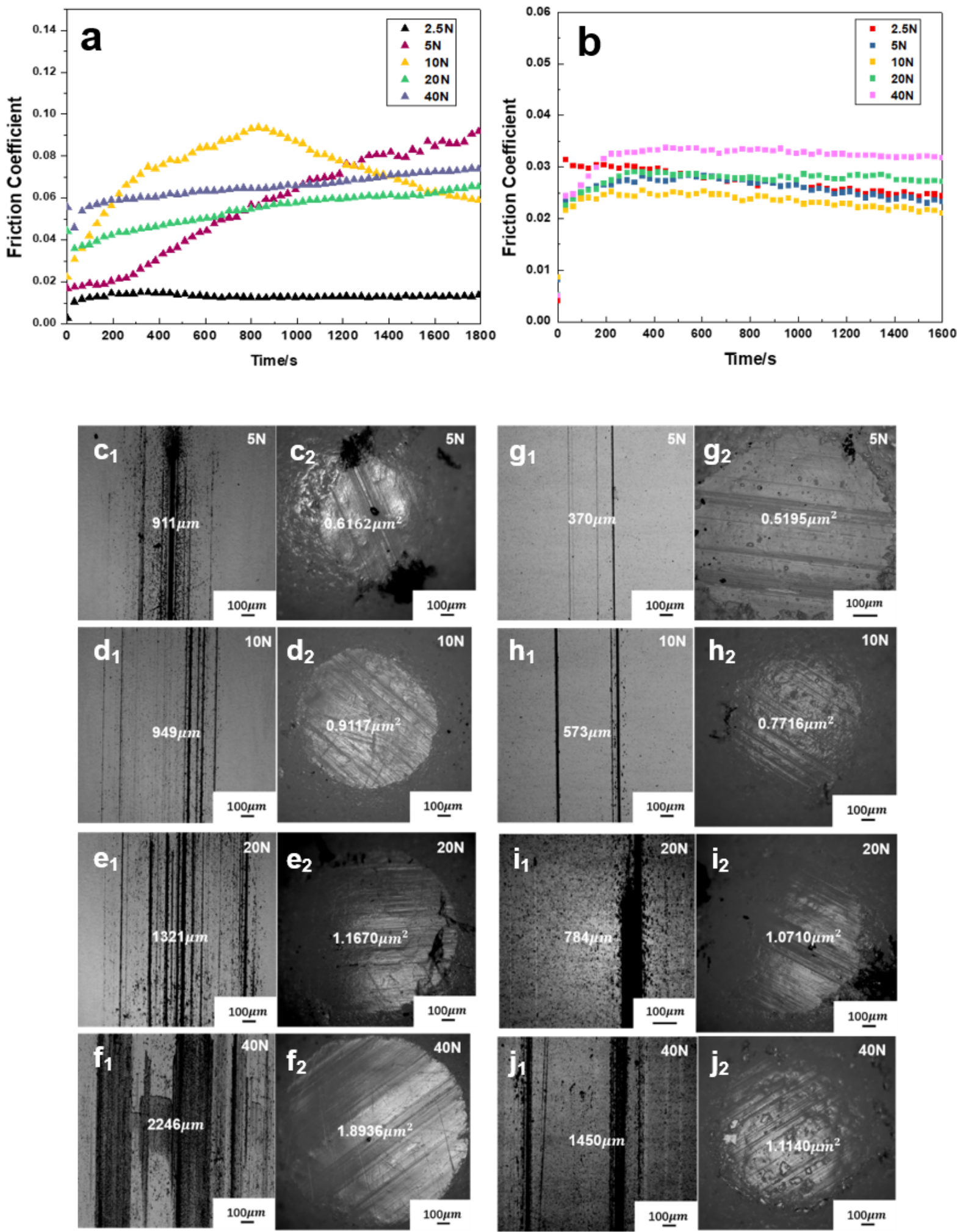

Figure 6. Tribological properties of bare Ti6Al4V and inorganic thermal oxide-coated Ti6Al4V at different loads: (a) friction coefficient of bare Ti6Al4V versus time; $(\mathbf{b})$ friction coefficient of inorganic thermal oxide-coated Ti6Al4V versus time; $\left(\mathbf{c}_{1}-\mathbf{f}_{\mathbf{1}}\right)$ wear morphologies of bare Ti6Al4V with applied loads of $\left(\mathbf{c}_{1}\right) 5 \mathrm{~N},\left(\mathbf{d}_{\mathbf{1}}\right) 10 \mathrm{~N},\left(\mathbf{e}_{1}\right) 20 \mathrm{~N}$, and $\left(\mathbf{f}_{\mathbf{1}}\right) 40 \mathrm{~N} ;\left(\mathbf{c}_{\mathbf{2}}-\mathbf{f}_{\mathbf{2}}\right)$ wear morphologies of PTFE balls (tribo-pairs of bare Ti6Al4V) with applied loads of $\left(\mathbf{c}_{2}\right) 5 \mathrm{~N},\left(\mathbf{d}_{2}\right) 10 \mathrm{~N},\left(\mathbf{e}_{2}\right) 20 \mathrm{~N}$, and $\left(\mathbf{f}_{2}\right) 40 \mathrm{~N}$; $\left(\mathbf{g}_{1}-\mathbf{j}_{\mathbf{1}}\right)$ wear morphologies of inorganic thermal oxide-coated Ti6Al4V with applied loads of $\left(\mathbf{g}_{\mathbf{1}}\right) 5 \mathrm{~N},\left(\mathbf{h}_{\mathbf{1}}\right) 10 \mathrm{~N},\left(\mathbf{i}_{\mathbf{1}}\right) 20 \mathrm{~N}$, and $\left(\mathbf{j}_{\mathbf{1}}\right) 40 \mathrm{~N} ;\left(\mathbf{g}_{\mathbf{2}}-\mathbf{j}_{\mathbf{2}}\right)$ wear morphologies of PTFE balls ( tribo-pairs of inorganic thermal oxide-coated Ti6Al4V) with applied loads of $\left(\mathbf{g}_{2}\right) 5 \mathrm{~N},\left(\mathbf{h}_{\mathbf{2}}\right) 10 \mathrm{~N},\left(\mathbf{i}_{\mathbf{2}}\right) 20 \mathrm{~N}$, and $\left(\mathbf{j}_{\mathbf{2}}\right) 40 \mathrm{~N}$. 


\subsection{Synergistic Effect of Inorganic Thermal Oxide Coating and Organic PVPA Coating}

In our previous work, we demonstrated the efficacy of organic PVPA coatings in the surface modification of artificial human joints [30]. Figure 7 shows the XPS survey scans of the modified surface. Lines I and III in Figure 7 represent the XPS survey of bare Ti6Al4V and organic PVPA coated Ti6Al4V, respectively. Compared to line I, the appearance of $\mathrm{P}$, the increase in $\mathrm{C}$, and the disappearance of Ti in line III demonstrate the successful modification of bare Ti6Al4V with organic PVPA. Our previous studies showed that the PVPA coating of PVPA-modified Ti6Al4V has a thickness of approximately $400 \mathrm{~nm}[24,30]$.

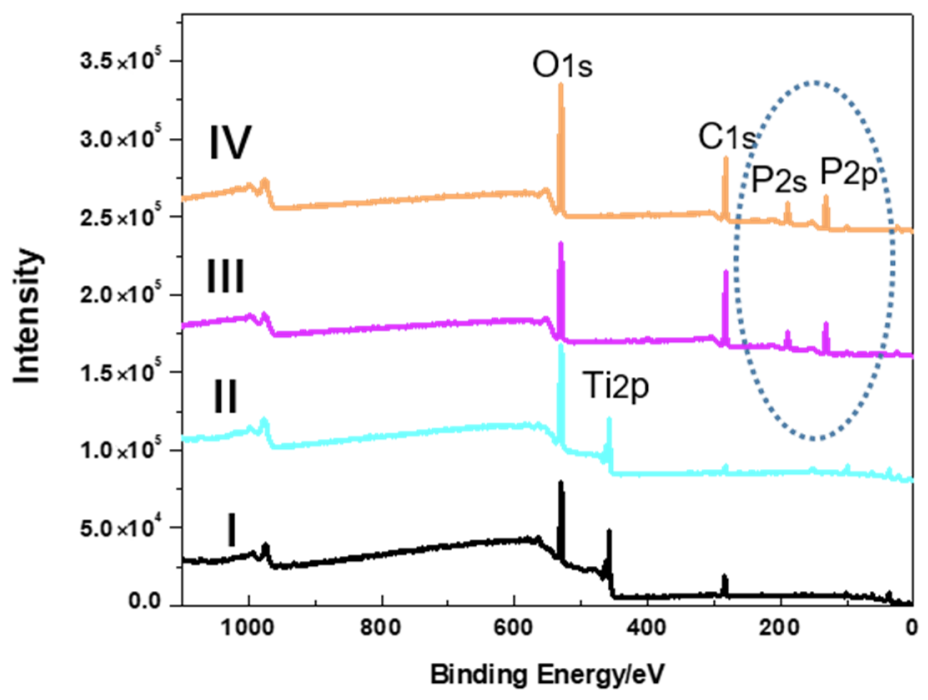

Figure 7. XPS survey scans of I: bare Ti6Al4V, II: Ti6Al4V heat treated at $300{ }^{\circ} \mathrm{C}$, III: organic PVPAcoated Ti6Al4V, and IV: inorganic thermal oxide/organic PVPA composite-coated Ti6Al4V.

Nanoindentation was performed on the sample to determine the elastic modulus, as shown in Figure 8. The elastic modulus of the organic PVPA-coated Ti6Al4V was $11.2 \pm 0.2 \mathrm{GPa}$, which corresponds to a stress of $21.42 \mathrm{MPa}$ at $2.5 \mathrm{~N}$.

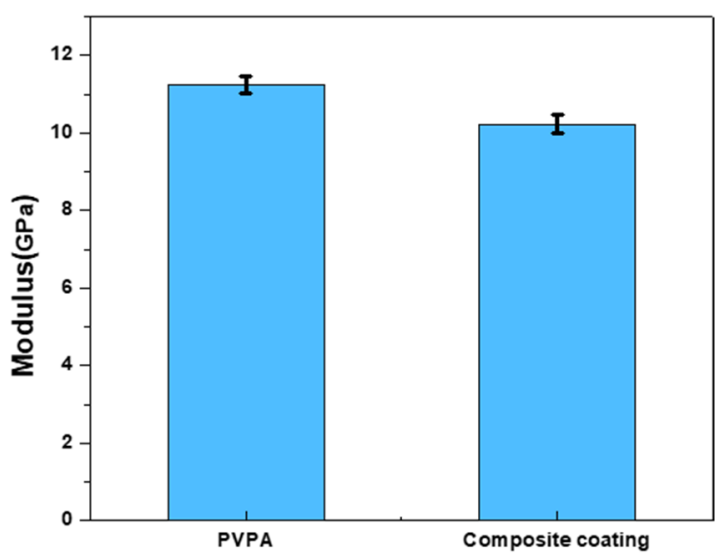

Figure 8. Elastic modulus of the PVPA- and composite-coated Ti6Al4V.

Friction experiments with different loads were conducted on the organic PVPA-coated Ti6Al4V. The results are shown in Figure 9. Compared to bare Ti6Al4V, the friction coefficient and wear of the organic PVPA-coated Ti6Al4V were significantly lower. At stresses of 21.42 MPa and $42.84 \mathrm{MPa}$, the friction coefficient of the organic PVPA-coated surface was lower than 0.01 . Thus, the organic PVPA coating can effectively reduce the friction coefficient and surface wear. 

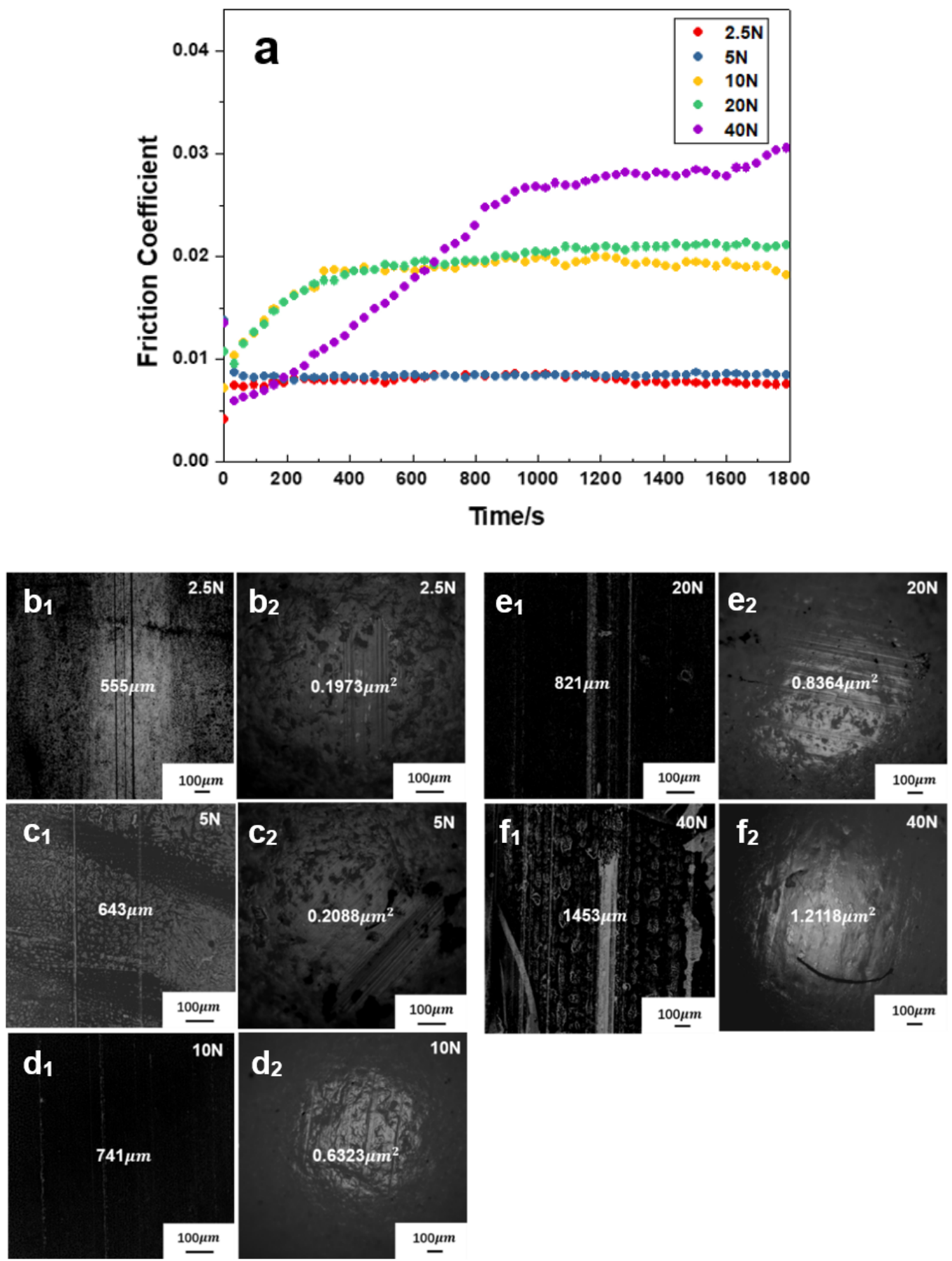

Figure 9. Tribological properties of organic PVPA-coated Ti6Al4V under different loads: (a) friction coefficient versus time; $\left(\mathbf{b}_{\mathbf{1}}-\mathbf{f}_{\mathbf{1}}\right)$ wear morphologies of organic PVPA-coated Ti6Al4V under loads of $\left(\mathbf{b}_{\mathbf{1}}\right) 2.5 \mathrm{~N},\left(\mathbf{c}_{\mathbf{1}}\right) 5 \mathrm{~N},\left(\mathbf{d}_{\mathbf{1}}\right) 10 \mathrm{~N},\left(\mathbf{e}_{\mathbf{1}}\right) 20 \mathrm{~N}$, and $\left(\mathbf{f}_{\mathbf{1}}\right)$ $40 \mathrm{~N} ;\left(\mathbf{b}_{\mathbf{2}}-\mathbf{f}_{\mathbf{2}}\right)$ wear morphologies of PTFE balls (tribo-pairs of organic PVPA-coated Ti6Al4V under loads of $\left(\mathbf{b}_{\mathbf{2}}\right) 2.5 \mathrm{~N},\left(\mathbf{c}_{\mathbf{2}}\right)$ $5 \mathrm{~N},\left(\mathbf{d}_{\mathbf{2}}\right) 10 \mathrm{~N},\left(\mathbf{e}_{\mathbf{2}}\right) 20 \mathrm{~N}$, and $\left(\mathbf{f}_{\mathbf{2}}\right) 40 \mathrm{~N}$.

An organic PVPA layer can be added to the inorganic thermal oxide coating to simulate articular joints. As shown in Figure 7, lines II and IV represent the typical XPS survey scans of inorganic thermal oxide-coated Ti6Al4V and composite-coated Ti6Al4V, respectively. Compared to line II, the appearance of $\mathrm{P}$, the increase in $\mathrm{C}$, and the disappearance of $\mathrm{Ti}$ in line IV indicate the suitability of adding organic PVPA on top of the inorganic thermal oxide coating. The elastic modulus of the composite-coated Ti6Al4V was $10.2 \pm 0.2 \mathrm{GPa}$, as shown in Figure 8. The corresponding stress of the composite-coated Ti6Al4V at $2.5 \mathrm{~N}$ 
was 21.36 MPa. The influence of the inorganic thermal oxide coating on the bearing effect of the PVPA coating was studied by changing the applied load, and the results are shown in Figure 10. The composite coating maintained a low friction coefficient of less than 0.01 at stresses of $85.44 \mathrm{MPa}$. At stresses of $170.88 \mathrm{MPa}$ and $341.76 \mathrm{MPa}$, the friction coefficients were 0.012 and 0.015 , respectively. Compared to the organic PVPA-coated Ti6Al4V, the bearing capacity of the composite-coated Ti6Al4V was increased by the presence of the thermal oxide coating in the composite coating. In the range of superlubricity, the presence of the inorganic thermal oxide coating increased the bearing capacity of the composite coating from $42.84 \mathrm{MPa}$ to $85.44 \mathrm{MPa}$.

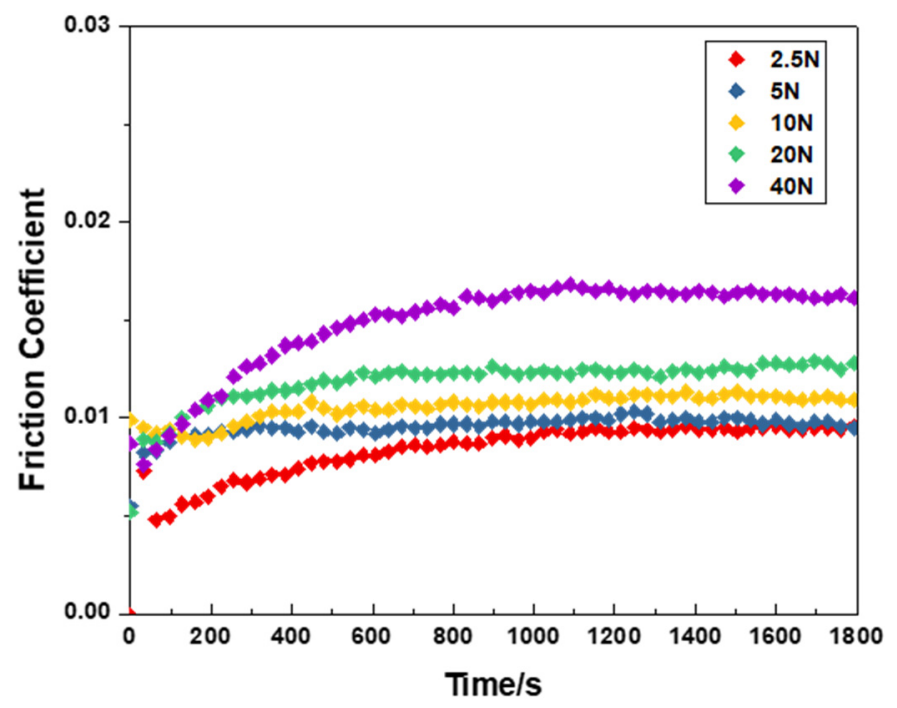

Figure 10. Friction coefficient of the composite coated Ti6Al4V versus time under different loads.

Organic PVPA surface modification can effectively reduce the friction coefficient and wear; at a stress of $42.84 \mathrm{MPa}$, the friction coefficient was less than 0.01. Compared to PVPA coating alone, the inorganic thermal oxide/organic PVPA composite coating had better bearing capacity. Owing to the inorganic thermal oxide coating, the composite coating had an ultra-low friction coefficient of less than 0.01 at a stress of $85.44 \mathrm{MPa}$. Thus, the friction coefficient of the composite coating is lower than that of the PVPA coating at high stress.

\section{Conclusions}

An inorganic thermal oxide/organic PVPA composite coating was designed and fabricated on to Ti6Al4V substrates that were subjected to various experiments. The synergistic regulation mechanism of the inorganic thermal oxide coating and the organic PVPA coating in terms of superlubricity were studied and analyzed. The results indicated that the organic thermal oxide coating can effectively improve the bearing capacity of the Ti6Al4V surface. Compared to bare Ti6Al4V, the thermal oxide-coated Ti6Al4V formed at $300{ }^{\circ} \mathrm{C}$ has 16 times higher bearing capacity. The increased hardness provided by the thermal oxide coating is the primary reason for the increase in the bearing capacity. The PVPA coating was found to effectively reduce the friction coefficient. It provides an ultralow friction coefficient of less than 0.01 at a stress of $42.84 \mathrm{MPa}$. The synergistic effect of the thermal oxidation layer and the PVPA was able to maintain an ultra-low friction coefficient of less than 0.01 even at a stress of $85.44 \mathrm{MPa}$. This study provides insights for the design and preparation of coatings with low friction and high load bearing capacity.

Author Contributions: Investigation, J.C., L.J. and X.L.; Supervision, Z.L.; Writing-original draft, M.L.; Writing-review \& editing, C.Z. All authors have read and agreed to the published version of the manuscript. 
Funding: The authors appreciate the funding supported by the National Natural Science Foundation of China (51705010, 51975019), the Beijing Natural Science Foundation (3192003), the General Project of Science and Technology Plan from Beijing Educational Committee (KM201810005013), the Tribology Science Fund of State Key Laboratory of Tribology (STLEKF16A02, SKLTKF19B08), the training program of Rixin talent and outstanding talent from Beijing University of Technology.

Institutional Review Board Statement: Not applicable.

Informed Consent Statement: Informed consent was obtained from all subjects involved in the study.

Data Availability Statement: Data is contained within the article.

Conflicts of Interest: The authors declare no conflict of interest.

\section{References}

1. Guo, Y.; Guan, J.; Peng, H.; Shu, X.; Chen, L.; Guo, H. Tightly adhered silk fibroin coatings on Ti6Al4V biometals for improved wettability and compatible mechanical properties. Mater. Des. 2019, 175, 107825. [CrossRef]

2. Liu, Z.; Liu, M.; Liu, Y.; Zhang, C.; Wang, X.; Ma, L.; Cai, H.; Cheng, Q. Molecular arrangement mechanisms within phosphate films on Ti6Al4V regulated by intermolecular forces based on sum frequency generation vibrational spectroscopy. Appl. Surf. Sci. 2020, 521, 146364. [CrossRef]

3. Fiołek, A.; Zimowski, S.; Kopia, A.; Sitarz, M.; Moskalewicz, T. Effect of Low-Friction Composite Polymer Coatings Fabricated by Electrophoretic Deposition and Heat Treatment on the Ti-6Al-4V Titanium Alloy's Tribological Properties. Metall. Mater. Trans. A Phys. Metall. Mater. Sci. 2020, 51, 4786-4798. [CrossRef]

4. Kruk, A.; Zimowski, S.; Łukaszczyk, A.; Cieniek, Ł.; Moskalewicz, T. The influence of heat treatment on the microstructure, surface topography and selected properties of PEEK coatings electrophoretically deposited on the Ti-6Al-4V alloy. Prog. Org. Coat. 2019, 133, 180-190. [CrossRef]

5. Lowe, S.; O'Brien-Simpson, N.M.; Connal, L.A. Antibiofouling polymer interfaces: Poly(ethylene glycol) and other promising candidates. Polym. Chem. 2015, 6, 198-212. [CrossRef]

6. Chouirfa, H.; Bouloussa, H.; Migonney, V.; Falentin-Daudre, C. Review of titanium surface modification techniques and coatings for antibacterial applications. Acta Biomater. 2019, 83, 37-54. [CrossRef]

7. Zeng, G.; Ogaki, R.; Meyer, R.L. Non-proteinaceous bacterial adhesins challenge the antifouling properties of polymer brush coatings. Acta Biomater. 2015, 24, 64-73. [CrossRef]

8. Ozcelik, B.; Ho, K.K.K.; Glattauer, V.; Willcox, M.; Kumar, N.; Thissen, H. Poly(ethylene glycol)-Based Coatings Combining Low-Biofouling and Quorum-Sensing Inhibiting Properties to Reduce Bacterial Colonization. ACS Biomater. Sci. Eng. 2016, 3, 78-87. [CrossRef]

9. Gao, Q.; Yu, M.; Su, Y.; Xie, M.; Zhao, X.; Li, P.; Ma, P.X. Rationally designed dual functional block copolymers for bottlebrush-like coatings: In vitro and in vivo antimicrobial, antibiofilm, and antifouling properties. Acta Biomater. 2017, 51, 112-124. [CrossRef]

10. Felgueiras, H.P.; Aissa, I.B.; Evans, M.D.; Migonney, V. Contributions of adhesive proteins to the cellular and bacterial response to surfaces treated with bioactive polymers: Case of poly(sodium styrene sulfonate) grafted titanium surfaces. J. Mater. Sci. Mater. Med. 2015, 26, 261. [CrossRef]

11. Martinez, J.; Pedemonte, F.; Galvin, M.B.; Gomez, J.S.; Barcena, M.M. Sliding Wear Behavior of UNS R56400 Titanium Alloy Samples Thermally Oxidized by Laser. Materials 2017, 10, 830. [CrossRef] [PubMed]

12. Lee, H.; Sungcheul, L.; Jong-Kweon, P.; Yang, M. Friction and Wear Characteristics of Surface-Modified Titanium Alloy for Metal-on-Metal Hip Joint Bearing. Int. J. Precis. Eng. Manuf. 2018, 19, 917-924. [CrossRef]

13. Wu, G.; Wang, Y.; Sun, M.; Zhang, Q.; Yao, J.; Kovalenko, V. Effect of laser surface melting pretreatment on the growth behavior and mechanical properties of microarc oxidation coating on Ti6Al4V alloy. J. Laser Appl. 2020, 32, 12013. [CrossRef]

14. Wang, S.; Liao, Z.; Liu, Y.; Liu, W. Different tribological behaviors of titanium alloys modified by thermal oxidation and spraying diamond like carbon. Surf. Coat. Technol. 2014, 252, 64-73. [CrossRef]

15. Wang, S.; Liao, Z.; Liu, Y.; Liu, W. Influence of thermal oxidation duration on the microstructure and fretting wear behavior of Ti6Al4V alloy. Mater. Chem. Phys. 2015, 159, 139-151. [CrossRef]

16. Melero, H.; Torrell, M.; Fernández, J.; Gomes, J.R.; Guilemany, J.M. Tribological characterization of biocompatible HAp-TiO2 coatings obtained by high velocity oxy-fuel spray. Wear 2013, 305, 8-13. [CrossRef]

17. Liu, D.; Ma, H.; Liang, Y.; Zheng, L. In vitro and in vivo biocompatibility and bio-tribological properties of the calcium/amorphousC composite films for bone tissue engineering application. Colloids Surf. B Biointerfaces 2020, 188, 110792. [CrossRef]

18. Ananth, M.P.; Ramesh, R. Sliding wear characteristics of solid lubricant coating on titanium alloy surface modified by laser texturing and ternary hard coatings. Trans. Nonferrous Met. Soc. China 2017, 27, 839-847. [CrossRef]

19. Vangolu, Y.; Alsaran, A.; Yildirim, O.S. Wear properties of micro arc oxidized and hydrothermally treated Ti6Al4V alloy in simulated body fluid. Wear 2011, 271, 2322-2327. [CrossRef]

20. Xiong, D.; Deng, Y.; Wang, N.; Yang, Y. Influence of surface PMPC brushes on tribological and biocompatibility properties of UHMWPE. Appl. Surf. Sci. 2014, 298, 56-61. [CrossRef]

21. Chen, M.; Briscoe, W.H.; Armes, S.P.; Klein, J. Lubrication at Physiological Pressures by Polyzwitterionic Brushes. Sci. Am. Assoc. Adv. Sci. 2009, 323, 1698-1701. [CrossRef] [PubMed] 
22. Ghosh, S.; Abanteriba, S.; Wong, S.; Houshyar, S. Selective laser melted titanium alloys for hip implant applications: Surface modification with new method of polymer grafting. J. Mech. Behav. Biomed. Mater. 2018, 87, 312-324. [CrossRef] [PubMed]

23. Ramakrishna, S.N.; Espinosa-Marzal, R.M.; Naik, V.V.; Nalam, P.C.; Spencer, N.D. Adhesion and Friction Properties of Polymer Brushes on Rough Surfaces: A Gradient Approach. Langmuir 2013, 29, 15251-15259. [CrossRef] [PubMed]

24. Zhang, C.; Liu, Y.; Wen, S.; Wang, S. Poly(vinylphosphonic acid) (PVPA) on Titanium Alloy Acting as Effective Cartilage-like Superlubricity Coatings. ACS Appl. Mater. Interfaces 2014, 6, 17571-17578. [CrossRef] [PubMed]

25. Zhang, C.; Liu, Z.; Liu, Y.; Ren, J.; Cheng, Q.; Yang, C. Novel tribological stability of the superlubricity poly (vinylphosphonic acid) (PVPA) coatings on Ti6Al4V: Velocity and load independence. Appl. Surf. Sci. 2017, 392, 19-26. [CrossRef]

26. Deng, Y.; Sun, J.; Ni, X.; Xiong, D. Multilayers of poly(ethyleneimine)/poly(acrylic acid) coatings on Ti6Al4V acting as lubricated polymer-bearing interface. J. Biomed. Mater. Res. Part B Appl. Biomater. 2020, 108, 2141-2152. [CrossRef] [PubMed]

27. Zhang, C.; Liu, Y.; Wen, S.; Luo, J. Insight into the formation mechanism of durable hexadecylphosphonic acid bilayers on titanium alloy through interfacial analysis. Colloids Surf. A Physicochem. Eng. Asp. 2014, 447, 51-58. [CrossRef]

28. Wang, S.; Liu, Y.; Zhang, C.; Liao, Z.; Liu, W. The improvement of wettability, biotribological behavior and corrosion resistance of titanium alloy pretreated by thermal oxidation. Tribol. Int. 2014, 79, 174-182. [CrossRef]

29. Li, A.; Su, F.; Chu, P.K.; Sun, J. Articular cartilage inspired bilayer coating on Ti6Al4V alloy with low friction and high load-bearing properties. Appl. Surf. Sci. 2020, 515, 146065. [CrossRef]

30. Zhang, C.; Liu, Y.; Liu, Z.; Zhang, H.; Cheng, Q.; Yang, C. Regulation Mechanism of Salt Ions for Superlubricity of Hydrophilic Polymer Cross-Linked Networks on Ti6Al4V. Langmuir 2017, 33, 2133-2140. [CrossRef] 